\title{
Effectiveness of IMNCI guideline on feeding problem among young infants (0-2 months) admitted in a selected hospital at Bhubaneswar, Odisha.
}

\author{
Geetarani Nayak \\ Department of Paediatric Nursing, SUM Nursing college / Siksha 'O' Anusandhan University, Khandagiri \\ square, Bhubaneswar, Odisha, India.
}

\begin{abstract}
Malnutrition and other preventable disease among the young children are caused mainly due to poor care and inappropriate infant feeding practices, delaying and restricting breast feeds and giving other products before six months. Development of feeding problem occur due to poor position and attachment. An evaluative approach was undertaken to assess feeding problem among 50 young infants (0-2months) admitted in IMS \& SUM Hospital, Bhubaneswar. The study design adopted was quasi experimental with one group pre-test and post-test design. The samples were selected by non probability convenience sampling. Pre-test and post test assessment was done by standard IMNCI guideline. The reliability was established 0.78 by using chronback's formula. Finding of the study shows that, comparison of pre test and post test assessment of ' $t$ ' value was 5.8 which were significant at $p<0.05$ level. It revealed that feeding problem among young infant were improved after administration IMNCI guideline.
\end{abstract}

Keyword:Effectiveness, Feeding problem, young infant, IMNCI guideline

\subsection{BACKGROUND OF THE STUDY}

\section{Introduction}

Adequate nutrition \& early feeding pattern are important determinants of health during infancy. Poor feeding during infancy can have lifelong effect. The best way to feed the young infant is to breast feed exclusively. Exclusive breast feeding gives a young infant the best nutrition and protection from diseases possible.

Breast feeding influences the child's health positively and improves nutritional status. A data analysis from those developing countries showed that infants who were not breast feed had a six fold greater risk of dying from infectious diseases within first two months of life than those who were breast fed (UNICEF 2007).

Six months of exclusive breast feeding and continued breast feeding in the first year of life could prevent 1.3 million child deaths worldwide.

Malnutrition has been responsible, directly or indirectly for $60 \%$ of the 10.9 million deaths annually among children under five. Over two thirds of these deaths, which are often associated with inappropriate feeding practices, occur during the first year.(Cochrane collaboration 2005)

National Institute of Environmental Health Sciences shows that children who are breast feed have a $20 \%$ of lower risk of dying between the age of 28 days and 1 year than children who were not breast fed.

Every year over one million infants die and millions of others are impaired because they are not adequately breast feed. Every day between 3000 to 4000 infants die from diarrhoea and ARI because the ability to feed them adequately has been taken away from their mothers.

Study suggest that maximal onset of breast feeding problems were noted in the first week after delivery. This is the period when mothers were more likely to fail to initiate breast feeding. The development of breast feeding problem occurs due to poor positioning of the baby.

Findings reveals that breast problems like cracked nipple, mastitis and sore nipple were significantly associated with poor positioning and attachment which are essential for effective breast feeding. Coce etel 2011 reported that women those infants were incorrectly positioned were 1.94 times at risk to developing nipple trauma compared with women whose nipple were correctly positioned.

\subsection{NEED FOR THE STUDY}

UNICEF 2008 reports that India has close to 25 million children born every year. Out of these 1.9 million are under five children, who die in a year. Among the deceased children, 1.4 million children die just within 1 year and roughly one million children dying with malnutrition and other preventable diseases caused mainly due to poor care and inappropriate infant feeding practices, delaying and restricting breast feeds and giving other products before six months are still common practices which increases the risk of infection, allergy, long term diseases and death 
Neonatal mortality contributes to over $64 \%$ of infant deaths and most of the deaths occur during first week of life. Mortality rate in second month of life is also higher than at later age.

W H O ,in collaboration with UNICEF and many other agencies, institution and individuals responded to this challenges by developing a strategy known as Integrated Management of Neonatal and Childhood Illness (IMNCI) to reduce death and improve growth and development of young infants(0-2 months).

A study was conducted in rural health and training centre of North India among mothers of children aged 2 years and those breast feeding at the time of study. The data was collected by using standard IMNCI breast feeding guidelines. After recording the pre intervention observation related to position and attachment of the baby while breast feeding, a demonstration of correct breast feeding practice was made was made to mothers as per IMNCI guidelines. Post intervention observation was done after gap of 10-15 days. The result showed that $82.8 \%$ of mothers were keeping baby close to them,89.7\% mothers kept baby's neck straight or slightly bent backwards while breastfeeding and significant number of babies were sucking deep and well in post intervention period .Out of 20 mothers with babies under 6 months , 8 mothers $(40 \%)$ had shown correct position following intervention as compared to $27 \%$ of mothers with babies over 6 months .Similarly with respect to attachment, $50 \%$ of mothers had shown improvement following intervention. So, it is concluded that in this study the IMNI guidelines helped mothers in bringing the babies close to them. By adopting the guideline the attachment of baby also improved.

\subsection{OBJECTIVES OF THE STUDY}

- To evaluate the feeding problem among the young infant (0-2 months) before and after administration of I M N C I guideline.

- To find out the association between feeding problem and selected demographic variables.

- To find out the effectiveness of IMNCI guidelines regarding feeding problem

2.1) Research Approach \& research design

\section{Material \& Methods}

Evaluative approach and quasi experimental design was adopted for the present study.

$\mathrm{O}_{1}-\mathrm{X}-\mathrm{O}_{2}$

$\mathrm{O}_{1}$ - Assessment of feeding problem among young infant before administration of IMNCI guideline.

$\mathrm{X}$ - Administration of IMNCI guideline.

$\mathrm{O}_{2}$ - Assessment of feeding problem among young infant after administration of IMNCI guideline.

2.2) Setting

The present study was conducted in IMS \&SUM Hospital, Bhubaneswar,

Odisha, India

2.3) Sample \& Sampling technique

50 young infants of 0-2 months of age were selected as the sample. Non probability convinient sampling technique was selected for the present study.

2.4) Tools

Standardized IMNCI assessment Performa to assess the feeding problems of young infants (0-2 months).

It comprised of two sections:-

Section I - Comprised of items seeking information on variables of children and their families

Section II - Comprised of standardized IMNCI assessment Performa to assess the feeding problems of young infants (0-2 months)

2.4.1) Validity -_To ensure content validity, the tool was submitted to five experts of different fields of nursing.

2.4.2) Reliability - The reliability of the baby scale were established by using Chronbach's formula and found to be 0.77 .

2.5) Plan for data analysis - The data obtained were analyzed using descriptive and inferential statistics.

2.6) Procedure of Data Collection - On day one, feeding problems were assessed by standardized IMNCI guidelines. After assessment, IMNCI guidelines were administered in terms of teaching and demonstrating mothers of children (0-2 months). After administration of IMNCI guidelines, feeding problems were assessed after two days in age group (0-2 months).

2.7) Conceptual framework - Based on Imogene King's Theory

\subsection{Regarding baby}

\section{Results}

- Majority (60\%) babies were within 1-7 days old.

- Majority (56\%) babies were having 2000-3000 gm weight.

- Majority (36\%) babies were LBW babies. 
Regarding mother

- Majority (42\%) mothers were between 26-30 yrs old.

- Majority (50\%) mothers were graduate.

- Majority (60\%) mothers were Hindu.

- Majority (54\%) mothers were housewives.

- Majority $(68 \%)$ mothers were primi paras.

- Majority (56\%) mother had delivered by LSCS.

- Maximum number of children (76\%) had feeding problem, $(24 \%)$ children had no feeding problem before administration of IMNCI guidelines and (14\%) children had feeding problem whereas $(86 \%)$ had no feeding problem after administration of IMNCI guidelines.

Table-I Frequency and percentage distribution of young infants (0 - 2 months) receiving other fluids before and after administration of IMNCI guidelines.

\begin{tabular}{|c|c|c|c|c|}
\hline \multirow{2}{*}{$\begin{array}{l}\text { Receiving Other } \\
\text { Fluids }\end{array}$} & \multicolumn{2}{|c|}{$\begin{array}{l}\text { Before Administration of IMNCI } \\
\text { Guidelines }\end{array}$} & \multicolumn{2}{|c|}{$\begin{array}{l}\text { After Administration of } \\
\text { IMNCI Guidelines }\end{array}$} \\
\hline & Frequency & Percentage & Frequency & Percentage \\
\hline Yes & 12 & 24 & 5 & 10 \\
\hline No & 38 & 76 & 45 & 90 \\
\hline \multicolumn{5}{|l|}{ If Yes } \\
\hline \multirow{2}{*}{$\begin{array}{l}\text { No of times } \\
\text { receiving other } \\
\text { fluids in } 24 \\
\text { hours }\end{array}$} & \multicolumn{2}{|c|}{$\begin{array}{l}\text { Before Administration of IMNCI } \\
\text { Guidelines }\end{array}$} & \multicolumn{2}{|c|}{$\begin{array}{l}\text { After Administration of } \\
\text { IMNCI Guidelines }\end{array}$} \\
\hline & Frequency & Percentage & Frequency & Percentage \\
\hline 2 - 4 Times & 5 & 10 & 2 & 4 \\
\hline 4 - 5 Times & 7 & 14 & 5 & 10 \\
\hline \multirow{2}{*}{$\begin{array}{l}\text { Methods of } \\
\text { giving foods and } \\
\text { drinks }\end{array}$} & \multicolumn{2}{|c|}{$\begin{array}{l}\text { Before Administration of IMNCI } \\
\text { Guidelines }\end{array}$} & \multicolumn{2}{|c|}{$\begin{array}{l}\text { After Administration of } \\
\text { IMNCI Guidelines }\end{array}$} \\
\hline & Frequency & Percentage & Frequency & Percentage \\
\hline Bottle & 3 & 6 & 0 & 0 \\
\hline Katori Spoon & 2 & 4 & 5 & 10 \\
\hline $\begin{array}{l}\text { Bottle }+ \text { Katori } \\
\text { Spoon }\end{array}$ & 7 & 14 & 0 & 0 \\
\hline
\end{tabular}

Data presented in Table 1 shows that maximum $76 \%$ of young infant did not received other fluid and $24 \%$ of young infant had received other fluid before administration of IMNCI guidelines. Whereas, maximum $90 \%$ of young infant did not received other fluid and $10 \%$ of young infant had received other fluid after administration of IMNCI guidelines. This indicates that number young receiving other fluid had decreased after administration of IMNCI guidelines. The data further shows that maximum 14\% of young infant were receiving 4-5 times other fluids followed by $10 \%$ children were receiving other fluids $2-4$ times before administration of IMNCI guidelines, whereas, maximum $10 \%$ of young infant were receiving 4-5 times other fluids followed by $4 \%$ children were receiving other fluids 2-4 times after administration of IMNCI guidelines. This indicates that number of times of receiving other fluids by young infant had decreased. Further data reveals that majority of $14 \%$ young infant receiving other fluids by Bottle and Katori Spoon method, $6 \%$ by bottle and $4 \%$ by katori spoon method before administration of IMNCI guidelines, whereas, majority of $10 \%$ young infant receiving other fluids by Katori Spoon method after administration of IMNCI guidelines. This indicates that bottle feeding has been stopped after administration of IMNCI guidelines

Table II-Frequency and percentage distribution of young infant (0-2 months) according to number of breast feeding in $\mathbf{2 4}$ hour before and after administration of IMNCI guidelines

\begin{tabular}{|l|l|l|l|l|}
\hline $\begin{array}{l}\text { Number of BF in 24 } \\
\text { Hrs }\end{array}$ & \multicolumn{2}{|l|}{$\begin{array}{l}\text { Before Administration } \\
\text { IMNCI Guidelines }\end{array}$} & $\begin{array}{l}\text { After Administration of } \\
\text { IMNCI Guidelines }\end{array}$ \\
\hline & Frequency & Percentage & Frequency & Percentage \\
\hline < 5 Times & 1 & 2 & 0 & 0 \\
\hline 5 - 6 Times & 30 & 60 & 3 & 6 \\
\hline 6 - 7 Times & 5 & 10 & 4 & 8 \\
\hline 7 - 8 Times & 11 & 22 & 36 & 72 \\
\hline > 8 Times & 3 & 6 & 7 & 14 \\
\hline
\end{tabular}


Table III-Frequency and percentage distribution of children (0-2months) according to sign of attachment during breast feeding before and after IMNCI guideline

\begin{tabular}{|l|l|l|l|l|}
\hline $\begin{array}{l}\text { Sign } \\
\text { attachment }\end{array}$ & $\begin{array}{l}\text { Before } \\
\text { administration } \\
\text { of IMNCI } \\
\text { guideline }\end{array}$ & & $\begin{array}{l}\text { After } \\
\text { administration } \\
\text { of IMNCI } \\
\text { guideline }\end{array}$ & \\
\hline Not well attached & Frequency & Percentage & Frequency & Percentage \\
\hline Good attachment & 13 & 74 & 5 & 10 \\
\hline
\end{tabular}

Table IV-Frequency and percentage distribution of children (0-2months) according to suckling during breast feeding before and after administration of IMNCI guidelines

\begin{tabular}{|l|l|l|l|l|}
\hline $\begin{array}{l}\text { Suckling during } \\
\text { breast feeding }\end{array}$ & \multicolumn{2}{|l|}{$\begin{array}{l}\text { Before Administration of } \\
\text { IMNCI Guidelines }\end{array}$} & $\begin{array}{l}\text { After Administration of IMNCI } \\
\text { Guidelines }\end{array}$ \\
\cline { 1 - 5 } & Frequency & Percentage & Frequency & Percentage \\
\hline $\begin{array}{l}\text { Not Suckling } \\
\text { effectively }\end{array}$ & 38 & 76 & 6 & 12 \\
\hline $\begin{array}{l}\text { Suckling } \\
\text { effectively }\end{array}$ & 12 & 24 & 44 & 88 \\
\hline
\end{tabular}

$\mathrm{N}=50$

- With regard to correct positioning, $84 \%$ mothers had shown correct position following intervention as compared to $30 \%$ mothers. $88 \%$ mothers were keeping the baby close to them, $90 \%$ mothers kept babies' neck straight and slightly bend backwards while breast feeding in post intervention period.

Table V Mean, mean difference, standard deviation and " $t$ " value of feeding problem of children (02months) in terms of attachment and suckling before and after administration of IMNCI guidelines $\mathbf{N}=\mathbf{5 0}$ $\mathbf{t}(49)=2.01$ at $\mathbf{p}<0.05$ significant

\begin{tabular}{|l|l|l|l|l|l|l|}
\hline & & & & & & \\
\hline $\begin{array}{l}\text { Feeding problem } \\
\text { Before administration } \\
\text { IMNCI guidelines }\end{array}$ & of & 50 & Mean & SD & MD & T Value \\
\hline $\begin{array}{l}\text { After of administration } \\
\text { IMNCI guidelines }\end{array}$ & of & 50 & 24.7 & 16.5 & & \\
\hline
\end{tabular}

\section{Discussion}

Highly significant difference was found between pre \& post test score as evident by " $t$ " value with a mean difference 0.9 .

With regard to position \& attachment present study reveals that $84 \%$ mothers had shown correct position following intervention as compared to $30 \%$ mothers whereas $90 \%$ of mothers had shown improvement in attachment following intervention, which is similar to the study conducted by Gupta Madhu (2008), where she reported out of 20 mothers with babies under 6 months, 8 mothers (40\%) had shown correct position following intervention as compared to $27 \%$ mothers with babies over 6 months, with respect to attachment ,50\% of mothers with babies under 6 month had shown improvement following intervention.

Balwinder Kaur et.el (2012) reported out of 29, $3(10 \%)$ babies were not well attached before administration of IMNCI guideline whereas $29(100 \%)$ babies were having good attachment after intervention.

\section{Limitation}

The study findings could not be generalized because of following reasons:

$>$ Non probability purposive sampling

$>$ Limited sample size 50 mothers.

$>$ Time constraint

\section{Nursing Implication}

- The nurse educator should plan various strategies to educate the mothers regarding attachment, suckling and positioning during breast feeding. 
- The nurse administrator should develop policies and protocols to promote breast feeding \& wider research can be conducted to explore other aspects of feeding problem $\&$ breast feeding practices.

\section{Recommendation}

$>$ This study can be replicated on large sample in a different setting to have a wider applicability by generalization.

$>$ An experimental study can be done to evaluate the breast feeding practice among mothers in term of attachment, suckling, positioning before and after administration of IMNCI guidelines.

$>$ A similar study can be conducted among the mothers in the community.

\section{Conclusion}

Thus, it is concluded that the IMNCI guidelines were effective in reducing the feeding problem among young infants. IMNCI guideline helped the mother in bringing babies close to them. By adopting the guideline the attachment of baby also improved.Demonstration \& teaching of correct breastfeeding practices can reduce the feeding problem of the young 4 infant $\&$ it will contribute to reduce the IMR.

\section{Acknowledgements}

Special acknowledgement to Mrs Kamalini Mallick \& Madhusmita Sarangi who helped in collection of data for the study sample.

\section{Journals:}

\section{References}

[1] World Health Organization. Integrated Management of Neonatal and Childhood Illness-Physician Chart booklet 2005; 12-15.

[2] Banerjee B. An intervention study in malnutrition among infants in a tribal community of West Bengal. Indian Journal of Community Medicine 30 (1), 2005; 46-50.

[3] Gupta Madhu. Feasibility study of IMNCI guidelines in rural areas of North India. Indian Journal of Community Medicine, 33 (3), 2008, 201-03.

[4] AREGAI W, GEBRIEL H, Determination of breast feeding practice, the Ethiopian journal of health development, 18 (3 ) 2008 , 132 134.

[5] Kaur. Balwinder ,Bala Jyoti,Sheoran Poonam, Nutritional status , feeding problems of children, 8(7),2012,33-36.

[6] UNICEF Annual report -Global under Five Mortality (2008)

Books:

[7] Datta P. Text book of paediatric Nursing, $2^{\text {nd }}$ edn, New Delhi: Jaypee Brothers Publication, 2012.

[8] Ghai Piyush, Essentials of Paediatrics, $8^{\text {th }}$ edn, Indore :CBS publication,2012. 